\title{
Chapter 3 \\ Multiple Solutions, The Experience of Competence, and Interest
}

\author{
Kay Achmetli and Stanislaw Schukajlow
}

\begin{abstract}
In the project MultiMa, we have been investigating how students' learning is affected when they construct multiple solutions while solving real-world problems by applying multiple mathematical procedures. Three hundred seven ninth graders from twelve middle-track classes took part in this study involving four lessons. We tested students' experience of competence during the teaching unit as well as students' interest before and after the teaching unit. The results indicate that constructing multiple solutions has a positive influence on students' experience of competence but no effect on their interest in mathematics.
\end{abstract}

Keywords Experience of competence $\cdot$ Interest $\cdot$ Multiple solutions $\cdot$ Real-world problems

\subsection{Introduction}

Affect appears to be essential for students' learning and achievement. There have been a number of calls for the development of teaching methods that can improve students' affect (Di Martino et al., 2015). To answer these calls, we conducted an experimental intervention study aimed at investigating methods for improving students' affect. As interest in mathematics is an important affective variable (Schukajlow \& Krug, 2014) and the experience of competence is one of the so called "basic psychological needs" (Deci \& Ryan, 2000) that can contribute to interest development (Krapp, 2005), we decided to focus on these two variables in the present study. As solving real-world problems is an important part of mathematics education (Niss, Blum, \& Galbraith, 2007), we chose this type of task to investigate the effects of constructing multiple solutions by applying different mathematical procedures on students' interest and experience of competence.

\footnotetext{
K. Achmetli $(\varangle) \cdot$ S. Schukajlow

Department of Mathematics, University of Münster, Fliednerstraße 21, 48149 Münster, Germany e-mail: k_achm01@uni-muenster.de

S. Schukajlow

e-mail: schukajlow@uni-muenster.de

(C) The Author(s) 2019

M. S. Hannula et al. (eds.), Affect and Mathematics Education,

ICME-13 Monographs, https://doi.org/10.1007/978-3-030-13761-8_3 
In this article, we report the results of the experimental intervention study we conducted in order to investigate how multiple solutions for real-world problems by applying different mathematical procedures could affect students' interest and their experience of competence. Furthermore, we examined the role students' experience of competence has in students' interest development. Thus, we analyse the indirect effects of constructing multiple solutions on students' interest via their experience of competence as well as the indirect effects of students' prior interest on their interest at post-test via their experience of competence.

\subsection{Theoretical Background}

\subsubsection{Interest}

Interest is acknowledged as an important affective variable in the learning process, because it can affect students' attention, goals, and levels of learning (see Hidi \& Renninger, 2006, for a summary). Furthermore, it is closely connected to strategy use (Schiefele \& Schreyer, 1994), self-regulation (Pintrich, 1999), performance goals (Harackiewicz, Durik, Barron, Linnenbrink-Garcia, \& Tauer, 2008) and achievement in mathematics (Fisher, Dobbs-Oates, Doctoroff, \& Arnold, 2012; Köller, Baumert, \& Schnabel, 2001; Schiefele, Krapp, \& Schreyer, 1993). According to the selfdetermination theory of human motivation and the person-object theory of interest, it emerges from an individual's interaction with the environment and therefore represents a specific person-object relationship (Hidi \& Renninger, 2006; Krapp, 2005). More specifically, "whereas the potential for interest resides in the person, the environment and the content define the direction of interest and contribute to its development" (Hidi, 2006). Theories of interest distinguish between cognitive and emotional aspects, which regulate the development of interest (Hidi, Renninger, \& Krapp, 2004; Krapp, 2005) and are connected to situational and personal or individual interest dimensions (Hidi \& Renninger, 2006). A situational interest is an interest in a particular object, which is environmentally triggered and may or may not last (Hidi et al., 2004). Individual interest develops over time and is a relatively enduring predisposition over time that also refers to a psychological state (Hidi, 2006; Krapp, 1999). Both kinds of interest are closely connected, as they both can be associated with the psychological state of interest (Hidi, 2006; Krapp, 1999) and because a situational interest can grow into an individual interest (Hidi \& Renninger, 2006).

In conclusion, there are at least three important characteristic of the construct of interest (Frenzel, Pekrun, Dicke, \& Goetz, 2012). First, its state- and traitlike nature which reflects the level of temporal stability of this affective construct (Schukajlow, Rakoczy, \& Pekrun, 2017): situational interest concerned to be temporal more stable than individual interest. In the present study we addressed the individual interest. Second, interest is considered to be content specific (Hidi \& Renninger, 2006), which is why we focus on the domain of mathematics. And third, interest can be 
conceptualised as a multicomponent construct (Frenzel et al., 2012) and includes both emotional and cognitive components.

The conceptualization of interest development as an outcome of the interaction of a person and an environment has particular relevance, because educators can actively influence environmental aspects, by selecting resources that triggers students' situational interest (Hidi, 2006). This is especially important because many students are not intrinsically motivated to learn mathematics and only a few develop an above-average interest in mathematics (Heinze, Reiss, \& Rudolph, 2005). Moreover, students' interest in MINT subjects decrease over the years, while they are in school (Köller, Baumert, \& Schnabel, 2000; Kunter, 2005). However, we do not know much about how different methods of teaching in the classroom influence students' individual interest (Heinze et al., 2005) and how individual and classroom factors work together to increase or decrease interest (Carmichael, Callingham, Watson, \& Hay, 2009). There are some indications, that students' interest improves stronger in student-centred learning environments, where students have the possibility to work in groups, rather than in teacher-centred instructional settings (Lerkkanen et al., 2012; Schukajlow et al., 2012). A situation of collective interest, which can be created through an interest-dense situation (Bikner-Ahsbahs, 2004) while working on a cognitive demanding problem, may also improve students' individual interest. Because students spend most of their math-lesson time working on mathematical problems (Hiebert et al., 2003), and previous research has shown, that teachers can trigger students' situational interest by using appropriate learning materials (Mitchell, 1993), selecting interesting problems is a mandatory first step in fostering students' individual interest. As interest is subject- and object-specific (Hidi \& Renninger, 2006), students' interest develops according to task-specific characteristics such as an existing connection to reality (Krug \& Schukajlow, 2013; Pekrun et al., 2007; Schukajlow \& Krug, 2012a, 2012b) or a match between contexts and their personal background or preferences (Ku \& Sullivan, 2002; López \& Sullivan, 1992). Real-world tasks are connected to reality and, in comparison with intra-mathematical tasks, real-world tasks offer more opportunities for increasing the value of a problem for an individual by matching the context of a task with an individual's personal background and preferences. Therefore, solving real-world tasks might lead to higher interest. However, we know from previous studies that students' interest on problems with connection to reality is similar as for problem without connection to real-world (Schukajlow et al., 2012). In a recent study, students' interest in problems with connection to reality was even lower than their interest in problems without connection to reality (Rellensmann \& Schukajlow, 2017), taking the task-difficulty into account. Thus, the teaching method of real-world problems seems to be at least as much important for triggering students' interest as the problem that teachers chose for particular classes. 


\subsubsection{Experience of Competence}

According to the theory of self-determination of human motivation (Deci \& Ryan, 2000; Ryan \& Deci, 2000) it is assumed that humans are naturally endowed with a system of basic psychological needs (Deci \& Ryan, 2008). Three essential needs: competence, autonomy, and relatedness are postulated to be important not only for well-being and psychological growth, but also for a variety of developmental processes, including interest development (Deci \& Ryan, 2000). According to Deci and Ryan (1991) the "need for competence encompasses people's strivings to control outcomes and to experience effectance; in other words, to understand the instrumentalities that lead to desired outcomes and to be able to reliably effect those instrumentalities." Conclusively, competence refers to the desire to feel efficacious, to have an effect on one's environment, and to be able to attain valued outcomes (Deci 1998). The experience of competence playes an important role in social cognitive models of achievement motivation (Wigfield, Battle, Keller, \& Eccles, 2002) or in learning theories regarding self-regulation (Boekaerts \& Corno, 2005; Zimmerman $\&$ Schunk, 2001). It is furthermore closely related to other motivational constructs such as intrinsic motivation (Deci \& Ryan, 2000), ability beliefs (Wigfield \& Eccles, 2000), and goals (Hannula, 2006). It increases intrinsic motivation and interest in the learning activity (Hänze \& Berger, 2007; Krapp, 2005; Schukajlow \& Krug, 2014). These results were found in different studies from vocational education (Krapp, 2005) and from research in regular classrooms in science (Hänze \& Berger, 2007) and mathematics (Schukajlow \& Krug, 2014).

Furthermore, we address students' experience of competence, because if a person has positive experiences while engaging in mathematics, their individual interest can be improved (Mitchell, 1993; Renninger \& Hidi, 2002). The experience of competence and as well as the experience of autonomy found to be crucial factors that provide feedback about students' states of functioning and thus influence interest (Krapp, 2005). However, empirical results from research on multiple solutions only partly support this expectation (Schukajlow \& Krug, 2014). While the experience of competence had a nearly significant influence on students' interest, the influence of the experience of autonomy on interest was small and not significant. Thus, the experience of competence is the centerpiece of the current study.

As shown above, the experience of competence is an important basic need of students that should be fullfilled in order to positively influence their motivation and increase their interest in mathematics. Learning environments that aim to fulfil basic needs and to improve students' motivation are assumed to be student-centred (Hannula, 2006). Empirical evidence for a better development of motivational variables derives from the comparison on student-centred teaching in which cooperative learning are typically used with teacher-centred methods of instruction (Schukajlow et al., 2012; Slavin, Hurley, \& Chamberlain, 2003; Webb \& Palincsar, 1996). Comparable results have been revealed by studies about the effects of self-regulated learning (Minnaert, Boekaerts, \& Opdenakker, 2008) on students' affect, achievements, and their perceptions of their abilities (Marcou \& Lerman, 2007; Panaoura, Gagatsis, \& 
Demetriou, 2009). One important factor of self-regulatory skills are self-monitoring activities, which are closely connected to the experience of competence. That is why we used a student-centred learning environment for our current study.

\subsubsection{Multiple Solutions and Real-World Problems}

Gaining experience in solving problems in more than one way is viewed as crucial for learning (Silver, Ghousseini, Gosen, Charalambous, \& Font Strawhun, 2005), fostering the connectedness of knowledge (Levav-Waynberg \& Leikin, 2012), and leading to a deeper understanding of the learning subject (Neubrand, 2006). Accordingly, developing, comparing, and reflecting on multiple solutions are important instructional elements that are part of high-quality teaching standards in different countries (National Council of Teachers of Mathematics, 2000).

Studying the effects of constructing multiple solutions on cognitive outcomes is an important goal for research in mathematics education and has thereby been intensively investigated in the last decade. Several experimental studies have shown positive effects of constructing multiple solutions on achievement, understanding, creativity, and procedural flexibility in the domain of mathematics (Leikin \& Lev, 2007; Schukajlow \& Krug, 2012a, 2012b; Schukajlow, Krug, \& Rakoczy, 2015; Star \& Rittle-Johnson, 2009). Because there is evidence about the positive connection between interest and achievement (Köller et al., 2001), both cognitive and affective outcomes should be taken into account for high-quality mathematics teaching. However, the impact of constructing multiple solutions on students' affect have very rarely been taken into account. One exception is our previous study (Schukajlow \& Krug, 2014).

We investigated the effects of constructing multiple solutions while solving realworld problems on the topic of linear functions because the ability to solve such problems is an important goal of mathematics education (Niss et al., 2007), because such problems are important for students' current and future lives. Although there are many different features of real-world problems (see Maßß, 2010, for a summary), the common core of real-world problems is the demanding process of transferring information between reality and mathematics (Blum, Galbraith, Henn, \& Niss, 2007). However, successfully solving real-world problems requires much more than mathematizing processes. The wide range of required activities is described in modelling circles (Blum \& Leiss, 2007; Galbraith \& Stillman, 2006; Verschaffel, Greer, \& De Corte, 2000) and implies, among other practices, the correct use of mathematical procedures (Niss et al., 2007; Schukajlow et al., 2012), which are a key point of our current study.

Analyses of problem-solving activities (Blum et al., 2007; Pollak, 1979; Verschaffel et al., 2000) have shown that there are different ways to construct multiple solutions while solving real-world problems (Fig. 3.1). One type of multiple solutions results from different assumptions while solving real-world problems with missing information and leads to different outcomes (Schukajlow \& Krug, 2014). Another 


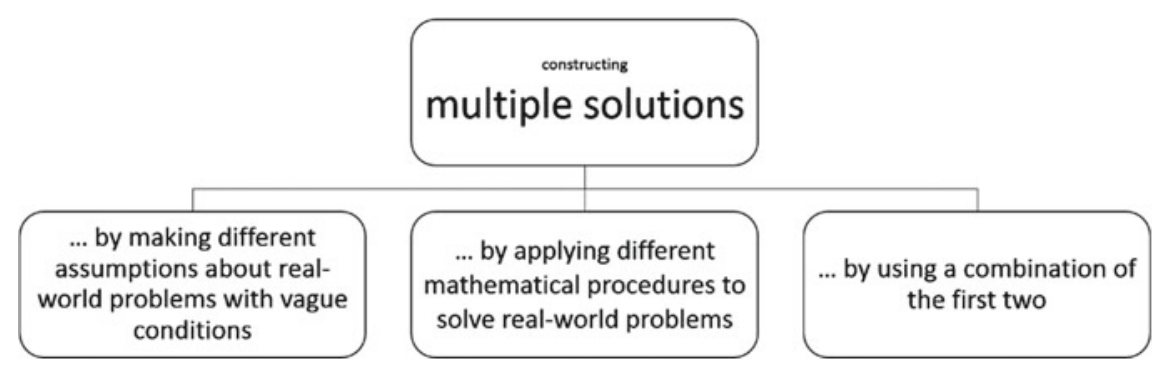

Fig. 3.1 Different categories of multiple solutions

BahnCard
Mr. Besser lives in Hamburg. His parents live in Bremen. For the outward and return
journeys with the "Deutsche Bahn" (German Rail), Mr. Besser has to pay $100 €$. There
are two special offers, the so-called "BahnCard 25 " and the "BahnCard 50 " The prices
for each year and the prices for the outward and return journeys from Hamburg to
Bremen for owners of the "BahnCards" are listed below.
\begin{tabular}{|l|l|}
\hline \multicolumn{1}{|c|}{ BahnCard 25} & \multicolumn{1}{c|}{ BahnCard 50} \\
\hline $\begin{array}{l}\text { Price per year: } 59 € \\
\text { Price for a round-trip journey: } 75 € \\
\text { Number of customers: } 3.1 \text { million }\end{array}$ & $\begin{array}{l}\text { Price per year: } 240 € \\
\text { Price for a round-trip journey: } 50 € \\
\text { Number of customers: } 1.6 \text { million }\end{array}$ \\
\hline
\end{tabular}
$\begin{aligned} & \text { Mr. Besser is going to buy a "BahnCard." When is it worth buying the "BahnCard } 25 \text { " and when the "BahnCard } 50 \text { "? } \\
& \text { Write down your solution. }\end{aligned}$

Fig. 3.2 Real-world task "BahnCard"

type of multiple solutions, addressed in the present study, results from applying different mathematical procedures or strategies while solving a problem and usually leads to the same mathematical outcome. The combination of these two types of multiple solutions is also possible and may be seen as a third type of multiple solutions.

To illustrate the two different mathematical procedures for real-world problems on the topic of linear functions that we focused on in the present study, we will present the process of solving the task "BahnCard," which was developed within the framework of our project (Fig. 3.2).

First, one has to understand the given problem and construct a model of the given situation. This model needs to be simplified and structured by identifying the important values. In the case of the task "BahnCard," these values are the prices per year for each card and the amounts that would be paid using each card for the round-trip journey. Next, the simplified model can be mathematized, and different mathematical procedures can be applied. One way to solve this problem is to apply the mathematical procedure "table." Students can make assumptions about a possible number of journeys per year and calculate the total costs for owners of the "BahnCard 25" and the "BahnCard 50." By comparing the costs for different numbers of journeys, they will be able to systematically identify the number of journeys that would make the "BahnCard 25" or the "BahnCard 50" a better deal. Another way to solve this 
problem is to apply the mathematical procedure "differences." Identifying the important values and calculating the differences for both of them, one recognizes that the "BahnCard 50" is $181 €(=240 €-59 €)$ more expensive than the "BahnCard 25," and each round-trip journey with the "BahnCard 25 " is $25 €(=75 €-50 €)$ more expensive than with the "BahnCard 50." Then the question arises as to how often one has to take a trip with the more expensive "BahnCard 50" until the cheaper price for the journey pays off, which is exactly after $7.24(=181 € \div 25 €)$ journeys per year. Finally, the outcomes of both mathematical procedures need to be interpreted and validated before one can present a recommendation about which offer is preferable for a certain number of journeys. In this case, the recommendation can be: "Starting with the eighth journey of the year, the BahnCard 50 is preferable. Otherwise, it is better to buy the BahnCard 25."

\subsection{Research Questions}

In this study, we addressed two research questions:

1. Does constructing multiple solutions while solving real-world problems affect students' experience of competence and their interest in mathematics?

2. How does constructing multiple solutions work together with the experience of competence and prior interest to improve students' interest at post-test?

\subsection{Hypothesised Path Model}

We applied a path model to the data, because we wanted to investigate whether and how intervention would work. Based on the theories about interest, the selfdetermination theory of motivation, and previous research, it allowed us to test predictions about possible factors (e.g., experience of competence) that transmit the effects of the experimentally manipulated treatment condition (e.g., MS vs. OS) on the outcome variables (e.g., interest at post-test).

The path analytic model (Fig. 3.3) is based on theoretical considerations about the effects of constructing multiple solutions by applying different mathematical procedures on students' experience of competence and their interest. We predicted that constructing multiple solutions would have a positive impact on students' experience of competence during the teaching unit and their interest at post-test. Furthermore, we predicted that experience of competence would lead to higher interest at post-test and that students' prior interest would have a positive influence on students' experience of competence and predict their interest at post-test. Finally, we expected indirect effects of constructing multiple solutions and prior interest on students' interest at post-test via their experiences of competence during the teaching, which results from the direct effects of the treatment on students' experiences of competence, the direct 


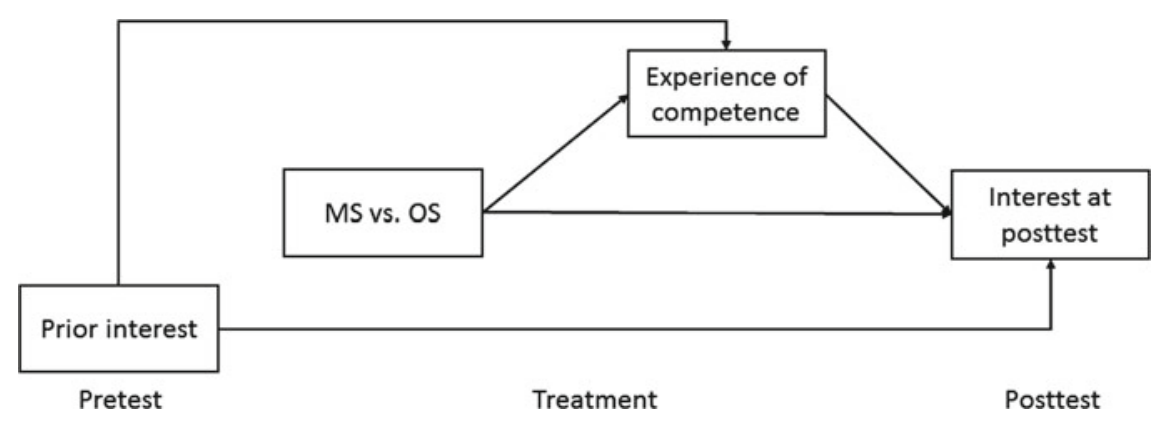

Fig. 3.3 Hypothesised path analytic model

effects of prior interest on students' experience of competence and from the direct effects from experiences of competence on interest at post-test and therefore do not needed a specific theoretical or empirical argumentation. For all of the described direct paths hypothesised in our path model above we found studies that had investigated single paths separately, only one study we found had a path model applied to the data to investigate indirect effects.

\subsubsection{Linking the Treatment Condition to the Experience of Competence}

Constructing more than one solution for one problem provides students with feedback about their competence in the learning situation (Schukajlow \& Krug, 2014) and positively affects their understanding of mathematics (Neubrand, 2006; Star \& Rittle-Johnson, 2009). Thus, we expected to find a positive effect of constructing multiple solutions by applying different mathematical procedures on students' experience of competence. The rationale behind this expectation is that students who are able to construct multiple solutions to solve a problem might feel more competent in mathematics than students who can find the solution using only one mathematical procedure. The positive influence of prompting students to find multiple solutions on the experience of competence was confirmed by Schukajlow and Krug (2014) who asked students to provide multiple solutions that result from different assumptions while solving real-world problems with missing information. The influence of constructing multiple solutions by applying multiple mathematical procedures on the experience of competence has yet to be investigated and is one question that we addressed in the present study. 


\subsubsection{Linking the Treatment Condition to Interest at Post-test}

Constructing multiple solutions to real-world problems provides students with the opportunities to discuss individual solutions during group work phases, to summarize possible links between different mathematical procedures, and to discuss differences and similarities between solutions, all of which in turn can improve students' interest (Schukajlow et al., 2012). As the development of interest is affected by cognitive aspects (Krapp, 2005) and the positive effect of using multiple solutions on cognitive aspects was found in prior studies (e.g., understanding and procedural flexibility; Rittle-Johnson \& Star, 2009), we expect positive effects of constructing multiple solutions on students' interest.

\subsubsection{Linking Experience of Competence to Interest at Post-test}

The link from experience of competence to interest at post-test has been supported by different empirical studies. Empirical evidence for the positive influence of students' experience of competence on their interest derives from vocational education (Krapp, 2005) and from research in regular classrooms in science (Hänze \& Berger, 2007) and mathematics (Schukajlow \& Krug, 2014). Furthermore, Students' self-concept at the beginning of a school year, which is conceptually related to their experience of competence (Wigfield \& Cambria, 2010), predicted their interest at the end of that year (Marsh, Trautwein, Lüdtke, Köller, \& Baumert, 2005). There is evidence on the topic of statistics that students' interest is influenced by their perceptions of their own competence (Carmichael et al., 2009). Students who report increases in their experience of competence also often report on a higher intrinsic motivation (Guay, Boggiano, \& Vallerand, 2001; Harter, Whitesell, \& Kowalski, 1992), which, according to Krapp (2005) is an interest-related motivational orientation. Additionally, Zimmerman and Kitsantas (1997) demonstrated that increased self-efficacy, which is frequently used interchangeably for experience of competence, was associated with increased interest.

\subsubsection{Linking Prior Interest to Experience of Competence and Interest at Post-test}

The relation between interest and self-efficacy might not be as unidirectional as stated above. Not only can increased experience of competence lead to an increase in interest, but through activities that are interest driven, individuals may change in a positive manner the ways in which they perceive their competence (Hidi, 2006). Thus, we hypothesised that prior interest would influence students' experience of 
competence positively, partly because it is an important factor for interest related motivational orientations and had been shown that it can positively influence the experience of competence (Marsh et al., 2005).

As interest is a stable construct, the link between prior interest and interest at posttest seems obvious and should not need further grounding. One exemplary empirical result is given by the study of Minnaert et al. (2008).

\subsection{Method}

\subsubsection{Sample}

The participants were 307 German ninth graders (48.26\% female; mean age 14.6 years) from four comprehensive schools (German Gesamtschule) with three middle-track classes each. Because in middle-track classes students from low- to high-achieving can be found, those classes were selected in order to increase the representativeness of the study. Students of the current sample did not have any formal experience in dealing with real-world problems nor did they have any prior knowledge in solving linear equation systems.

\subsubsection{Study Design}

Each of these classes were divided into two parts with the same number of students in each part in such a way that the average level of achievement in the two parts did not differ, and the ratio of males to females was approximately the same in each part. Using this method we generated six groups at each school.

In order to analyse the effects of constructing multiple solutions by applying two mathematical procedures on students' interest, we needed to control these effects in comparison to constructing only one solution. As previous studies on multiple solutions had underlined the importance of context factors (Große, 2014; Große \& Renkl, 2006), and the kind of mathematical procedures students apply represent such a contextual factor, it could be possible that different mathematical procedures lead to different outcomes. That is why we not only needed two (multiple solutions vs. one solution) but three treatment conditions (see next section).

Each group than was assigned to a treatment condition in such a way, that students of the same classes never were treated in the same treatment condition and that each treatment condition was evenly frequent at each school (Fig. 3.4).

To implement the treatment, which consisted of solving real-world problems using different mathematical procedures to solve each problem, the six teachers who participated in this study received instructional manuals containing all the tasks to be administered in each condition, the solutions to the problems, and a detailed plan for 


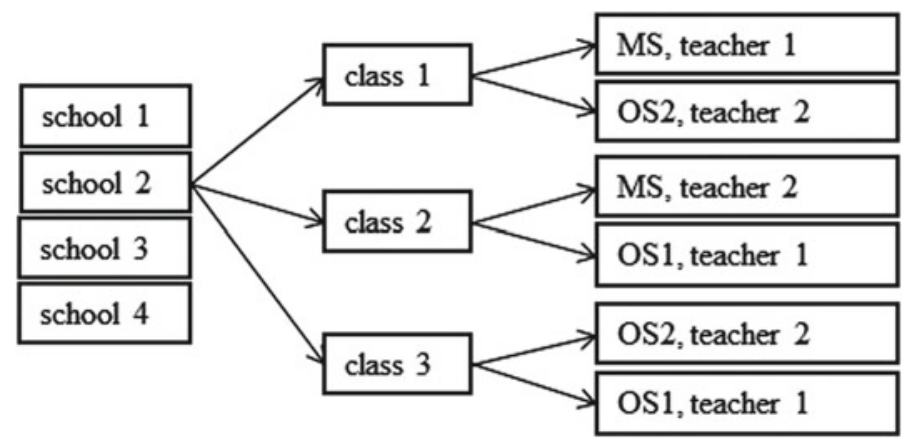

Fig. 3.4 Assignment of students to the treatment conditions

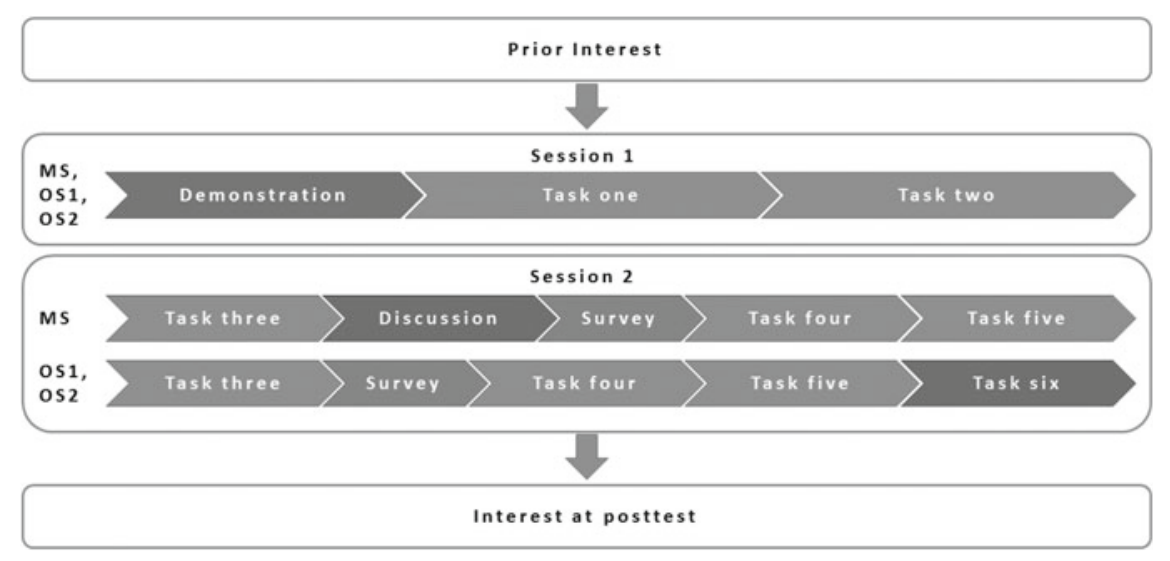

Fig. 3.5 Overview of the study design

the teaching unit. Each teacher taught the same number of student groups in each treatment condition, so the influence of a teacher on students' learning did not differ between conditions.

The research team provided the teachers with all real-world problems, the solution spaces, and manuals with lesson plans. Before the experiment began the key points of each treatment condition (see next section) were discussed in training for all participating teachers.

The teaching unit was carried out during regular classes and consisted of two sessions of each $90 \mathrm{~min}$. Students' were asked to report on their experience of competence during the teaching unit using a short survey (in the second session; Fig. 3.5). They were also asked about their interest in mathematics before and after the fourlesson teaching unit. Students did not have any regular mathematics classes during our current study, so the effects of constructing multiple solutions on students' interest and experience of competence was not falsified. 


\subsubsection{Treatment}

For the purposes of the study, three treatment conditions were implemented. In the multiple solution condition (MS), real-world problems were posed, and the students were prompted to apply two mathematical procedures. In both of the one-solution conditions (OS1 and OS2), similar problems were posed, but the task instructions indicated that only one solution was required (mathematical procedure "table" and mathematical procedure "differences" in OS1 and OS2, respectively). In the multiplesolution condition, one sample problem was the "BahnCard" problem (Fig. 3.2) with the following modification: "Use two different mathematical procedures to solve this problem." In the one-solution conditions, students solved the original version of the "BahnCard" problem.

All three treatment conditions were based on the positively evaluated studentcentred learning environment for teaching modelling problems from the DISUM Project (Schukajlow et al., 2009, 2012), which had demonstrated a positive influence on students' affect and learning. We complemented this learning environment by a direct instruction at the beginning. Students were instructed about the goals of the respective treatment condition, the key features of the problems that would be presented during the teaching unit and how such real-world problems could be solved using multiple mathematical procedures (in the MS condition) or one specific procedure (in the OS conditions). Then students solved tasks using the demonstrated procedures according to a special procedure for group work. At first, they worked individually and developed first ideas about how to solve the problem. Afterwards they worked cooperatively in groups of four and discussed their ideas for solving the problem. Subsequent they wrote down one's own individual solution by applying multiple mathematical procedures or one mathematical procedure. Following this group a voluntary student presented how to solve the problem applying one or two mathematical procedures respectively and the whole class discussed the solution. Finally, the teacher summarized the key points of each treatment condition. Furthermore, in the MS condition, the teacher emphasized the development of two different procedures and after the first task in the second session in the MS-condition, the teacher highlighted and summarized the links between the two mathematical procedures, compared and contrasted the mathematical procedures, and fostered discussions about students' preferences for one or the other procedure. In order to compensate the time needed for this phase, students in the OS conditions solved an additional task at the end of session two.

Four out of six tasks given in the MS condition required the development of two mathematical procedures: "Use two different mathematical procedures to solve this problem. Write both down." In the OS conditions, students solved a standard version of this task (see Fig. 3.2) using the demonstrated mathematical procedure. 
Table 3.1 Items used in the study to assess interest and experience of competence

\begin{tabular}{l|l}
\hline Scale & Item \\
\hline Interest (Frenzel et al., 2012) & $\begin{array}{l}\text { I am interested in mathematics } \\
\text { I like to read books and solve brain teasers related to } \\
\text { mathematics } \\
\text { Doing mathematics is one of my favorite activities }\end{array}$ \\
\hline Experience of competence & $\begin{array}{l}\text { I noticed that i really understood things (Hänze \& Berger, } \\
\text { 2007) } \\
\text { I felt able to master the work (Hänze \& Berger, 2007) } \\
\text { I felt confident about my knowledge about the topic today } \\
\text { (Schukajlow \& Krug, 2014) }\end{array}$ \\
\hline
\end{tabular}

\subsubsection{Measures}

Students' interest and experience of competence were assessed using two separate measures (Table 3.1). Each measure was assessed on a 5-point Likert scale ( $1=$ not at all true, $5=$ completely true).

Conceptually, interest can be differentiated in situational and individual interest. Thus, for the measurement of interest it is important to know, which kind of interest one is interested in measuring effects on. As individual interest is on a higher level of interest development (Hidi \& Renninger, 2006) and situational interest can contribute to individual interest, we decided to measure students' individual interest. It was measured using a scale that included three items from the Project for the Analysis of Learning and Achievement in Mathematics (PALMA-Project). These items refer to individual interest in the subject of mathematics, comprising of various components of the construct, including emotional and cognitive aspects: (a) "I am interested in mathematics," (b) "I like to read books and solve brain teasers related to mathematics," and (c) "Doing mathematics is one of my favourite activities" (Frenzel et al., 2012). These items measured students' individual interest in mathematics and have been validated using qualitative and quantitative methods.

For the measurement of students' experience of competence, three items from a well-evaluated scale by Schukajlow and Krug (2014) were used: (a) "I noticed that I really understood things," (b) "I felt able to master the work," and (c) "I felt confident about my knowledge about the topic today".

Both measures have been used in previous studies. The items measured students' interest in mathematics have been validated with qualitative and quantitative methods and revealed that each item assessed the emotional an personal dimensions of students' individual interest (Frenzel et al., 2012). In the current study, the reliability values (Cronbach's alpha) were 0.77 and 0.75 at pre-test and post-test, respectively, and were similar to the reliabilities found in another study (Schukajlow \& Krug, 2014). The scale experience of competence was based on three items that refer to understanding and mastering the assigned work. Two items were taken from the study by Hänze and Berger (2007) and one item was taken from the study by Schukajlow 
and Krug (2014). In the current study, the reliability of this scale is 0.74 and is therefore comparable to a previous study (Schukajlow \& Krug 2014).

\subsubsection{Data Analysis}

We started our analysis by examining the influence of the treatment conditions on "experience of competence" and "interest". In order to answer the second research question we applied a path model with 13 free parameters and 307 subjects to the data. The ratio of subjects to parameters was above the critical value of 5 for obtaining correct results (Kline, 2005) and therefore sufficient for addressing the research question. In all analyses, dummy codes for the treatment factor $(0=\mathrm{OS} ; 1=\mathrm{MS})$ were used.

Another important factor that needs to be accounted for is the possible clustering of the data. As we wanted to increase the external validity of our study, students were instructed in small groups of 9-16 students from the same mathematics class rather than individually. Students of the same class were assigned to a randomly chosen treatment condition, taking into account their achievement. To examine the degree of dependence within these groups $(n=24)$ for students' prior interest, we calculated the intraclass correlation coefficient (ICC) using the statistical program Mplus (Muthén \& Muthén, 1998-2012) and transformed them into design effects (Muthén \& Satorra, 1995) to indicate the loss of statistical power due to the dependence of observations. As the ICC was low (0.038) the resulting design effect of 1.41 is below the critical value of 2 (Muthén \& Satorra, 1995). Furthermore, the within-group variability was significant $(p<0.001)$, and the between-group variability was not significant $(p$ $>0.10)$. As there are no significant clustering effects of interest within treatment conditions, no statistical control was needed.

To answer the second research question we needed to test indirect effects. An indirect effect is the product of two direct paths. We estimated standard errors using a bootstrapping approach, which is one of the preferable methods for testing indirect effects (MacKinnon, Lockwood, Hoffman, West, \& Sheets, 2004). Ten-thousand bootstrap samples were drawn and bootstrap percentiles are used to form the $95 \%$ non-symmetric bootstrap confidence interval (CI) (Muthén, Muthén, \& Asparouhov, 2016). The null hypotheses (there is no direct/ indirect effect) was rejected if zero was not included in the $95 \%$ CI. Therefore all effects of the path model will be reported with their respective $\mathrm{CI}$ rather than with a $p$-value.

The chosen method of the current study allowed us to directly test the significance of the indirect effect (MacKinnon, 2008), which is the preferable method compared to a stepwise regression method (e.g., Baron \& Kenny, 1986), because it has a higher statistical power at a comparable Type I error (MacKinnon, Lockwood, Hoffman, West, \& Sheets, 2002). Furthermore, the existence of a total effect is not required if the indirect effect is directly tested (MacKinnon, 2008).

Missing values are an important issue typically found in longitudinal studies. In the current study the percentage of missing values differed across the measures from 
$7.5 \%$ for experience of competence to $8.5 \%$ for interest at post-test. The use of the full information likelihood estimator or multiple imputation are the preferred solution to address the problem of missing values (Peugh \& Enders, 2004). We decided to use the full information likelihood algorithm implemented in Mplus (Muthén \& Muthén, 1998-2012), which uses the full information of the covariance matrices to estimate the missing values. Taking into account the missing at random assumption, the usage of this algorithm, should not have a bias for the estimation of our model parameters (Schafer \& Graham, 2002).

\subsubsection{Treatment Fidelity}

All participating teachers were experienced in teaching real-world problems and were further instructed for one day with regard to the teaching method they should apply. In each lesson, at least one member of the research group was present in order to administer tests and assessment scales and to videotape and observe the implementation of the treatment. Furthermore, all of the students' written work was collected. The analysis of the videos and students' solutions revealed that the time spent on the tasks did not differ across the conditions and that the tasks were solved as intended for each condition. As intended teachers in the MS condition needed more time after the first task than in the OS conditions to highlight and summarize the links between the two mathematical procedures and to foster a discussion about students' preferences for one or the other procedure. This was consistent in all MS conditions and was compensated by an additional task for the OS condition which was solved in all groups and discussed as intended.

Another important aspect of our treatment fidelity involved the number of mathematical procedures students used during the treatment (see Achmetli, Schukajlow, $\&$ Krug, 2014). Theoretically, the number could range from 0 (no mathematical procedure) to 3 (more than two mathematical procedures). For our analysis, two independent raters rated $20 \%$ of the tasks with a high level of agreement (Cohen's Kappa between 0.89 and 0.94). As intended in our study, nearly all students in the MS condition used two or more mathematical procedures (mean $M=1.92$, standard deviation $S D=0.25$ ), whereas in the OS conditions, students did not or rarely constructed two or more mathematical procedures $(M=1.01, S D=0.08$ and $M=1.04$, $S D=0.24) . T$-tests indicated that there were highly significant differences between the conditions in the number of mathematical procedures that students used to solve the problems (MSM vs. OSM1: $t(116)=34.0 ; p<0.001$; effect size Cohen's $d=$ 4.97 and MSM vs. OSM2: $t(194)=25.2 ; p<0.001 ; d=3.61)$. 
Table 3.2 Students' interest on the pre-test and post-test and their experience of competence during the teaching unit in the one-solution conditions

\begin{tabular}{|c|c|c|c|c|c|}
\hline \multirow[t]{2}{*}{ Variable } & OS1 & OS2 & \multirow{2}{*}{$\begin{array}{l}t(d f= \\
186)\end{array}$} & \multirow[t]{2}{*}{$p^{*}$} & \multirow[t]{2}{*}{$d$} \\
\hline & $M(S D)$ & $M(S D)$ & & & \\
\hline Prior interest & $2.38(0.95)$ & $2.40(0.97)$ & -0.182 & 0.856 & 0.03 \\
\hline Experience of competence & $4.21(0.87)$ & $4.22(0.75)$ & -0.310 & 0.975 & 0.00 \\
\hline Interest at post-test & $2.51(0.98)$ & $2.49(0.82)$ & 0.135 & 0.892 & 0.02 \\
\hline
\end{tabular}

*Two-tailed

\subsection{Results}

\subsubsection{Preliminary Results and Analysis of Treatment Effects}

As our statistical analysis for all three variables did not show a difference at the $5 \%$ level of significance between the two OS conditions (Table 3.2), and in order to simplify the analysis of the effects, we combined the OS1 and OS2 conditions into one OS condition.

Furthermore, the analysis of interest on the pre-test revealed no differences between the MS and OS conditions (MS: $M=2.39$ ( $S D=0.90)$, OS: $M=2.39$ (SD $=0.96)$ ). Similar results were also found for self-regulation (Achmetli et al., 2014). These results indicate similar motivational prerequisites in the two conditions.

\subsubsection{Effects of Constructing Multiple Solutions on Experience of Competence and Interest in Mathematics}

In order to compare the interest between the MS and OS condition at post-test, we took students' prior interest into account and calculated an adjusted post-test value for each student. Students' interest tended to be higher in the MS condition, but a $t$ test showed that there were no significant differences ( $p=0.313$; effect size: Cohen's $d=0.13$ ) between the two conditions (Table 3.3). Thus, constructing multiple solutions for real-world problems by applying multiple mathematical procedures did not have a positive effect on interest. According to this result, students who applied multiple mathematical procedures during the teaching unit reported a level of interest in mathematics that was comparable to students who used only one mathematical procedure.

Students in both conditions experienced a high level of competence (MS: mean $=$ $4.44((S D)=0.60)$, OS: $M=4.21(S D=0.81))$. To examine the influence of multiple solutions for real-world problems by applying multiple mathematical procedures on students' experience of competence, we used a $t$-test. Levene's test showed that there 
Table 3.3 Students' adjusted interest on the pre-test and their experience of competence during the teaching unit in the multiple-solution condition and one-solution condition

\begin{tabular}{|c|c|c|c|c|c|}
\hline \multirow[t]{2}{*}{ Variable } & MS & OS & \multirow{2}{*}{$\begin{array}{l}t(d f= \\
279)\end{array}$} & \multirow[t]{2}{*}{$p^{*}$} & \multirow[t]{2}{*}{$d$} \\
\hline & $M(S D)$ & $M(S D)$ & & & \\
\hline Experience of competence & $4.44(0.60)$ & $4.21(0.81)$ & 2.361 & 0.019 & 0.30 \\
\hline Adj. interest at post-test & $2.58(0.71)$ & $2.49(0.70)$ & 1.011 & 0.313 & 0.13 \\
\hline
\end{tabular}

*Two-tailed

was heterogeneity of variance; therefore, we used the adjusted degrees of freedom and $t$-values. The results indicated that there were significant differences between the MS condition and the OS condition $(t(231)=2.616 ; p<0.05 ; d=0.30)$. Thus, students in the MS condition reported a higher experience of competence than students in the OS condition.

\subsubsection{Statistical Procedure and Analysis of Model Fit}

The maximum-likelihood algorithm implemented in Mplus was used for the statistical analyses of the path model (Muthén \& Muthén, 1998-2012). This algorithm allows the calculation of fit values for the path model in order to analyse whether the data provide a good fit to the hypothesised model or not. We applied a combination of cut-off values (Hu \& Bentler, 1999) of the comparative fit index (CFI) $>0.95$, the standardized root mean square residual $(\mathrm{SRMR})<0.08$ and the root mean square error of approximation (RMSEA) $<0.06$ and aimed for a ratio of $\chi^{2}$ and $d f$ below 2.5. The hypothesised model fit the data well according to all fit indexes $\left(\chi^{2} / d f=0.02\right.$; $\mathrm{RMSEA}=0.00,90 \% \mathrm{CI}[0.00,0.07], p=0.925 ; \mathrm{CFI}=1.000 ; \mathrm{SRMR}=0.003)$ and $40 \%$ of the variance in interest at post-test could be explained by this model.

The calculated correlation matrix of the variables measured in the current study is presented in Table 3.4. The analysis of the values showed that all the correlations were in the expected direction (e.g., both interest measures were significantly correlated with each other and all correlations between interest and experience of competence were positive).

\subsubsection{Direct and Indirect Effects on Students' Interest}

In this section, we present the results of the estimates calculated for the hypothesised path model. Because the treatment conditions represented a binary factor (MS vs. OS), StdY values were used to calculate the standardized estimates in Mplus. Thus, $\beta$ coefficients may be interpreted as the predicted change in (residualised) criterion measures (in standard deviation units) when the treatment changes from 0 (one solu- 
tion) to 1 (multiple solutions). Confidence intervals are used to identify significant regression coefficients and are presented in Table 3.5.

The analysis of the path model (Fig. 3.6) reveals that the treatment condition predicts students' experience of competence during the teaching unit $(\beta=0.14 ; 95 \%$ CI $[0.04,0.25])$ but not their interest at post-test $(\beta=0.05 ; 95 \%$ CI $[-0.04,0.14])$. Another result was a significant prediction of students' experience of competence from their prior interest $(\beta=0.21 ; 95 \%$ CI $[0.07,0.35])$. Furthermore, students' interest at post-test is predicted by their prior interest $(\beta=0.64 ; 95 \%$ CI $[0.53$, $0.74]$ ) but not by their experience of competence during the teaching unit $(\beta=-$ $0.04 ; 95 \%$ CI $[-0.16,0.07])$.

One of the main reasons for using a path model is the analysis of indirect effects. We analysed two indirect effects on students' interest at post-test: From the treatment condition through the experience of competence and from students' prior interest via the experience of competence. The main result of the path model is that there are no significant indirect effects of the treatment condition on students' interest via their experience of competence $(\beta=-0.01 ; 95 \%$ CI [ $-0.02,0.01])$. Conclusively and consistent to the result of the treatment effects, there are no total effects of the treatment condition on students interest at post-test $(\beta=0.04 ; 95 \% \mathrm{CI}[-0.05,0.14])$. Moreover, there are no significant indirect effects of students' prior interest on their interest at post-test via their experience of competence during the teaching unit ( $\beta$

Table 3.4 Correlations among the measures

\begin{tabular}{l|l|l|l}
\hline Variable & Prior interest & $\begin{array}{l}\text { Experience of } \\
\text { competence }\end{array}$ & $\begin{array}{l}\text { Interest at } \\
\text { post-test }\end{array}$ \\
\hline $\begin{array}{l}\text { 1. Prior interest } \\
\begin{array}{l}\text { Experience of } \\
\text { competence }\end{array}\end{array}$ & - & & \\
\hline 3. Interest at post-test & $0.62^{*}$ & - & \\
\hline
\end{tabular}

${ }^{*} p<0.01$, two-tailed

Table 3.5 Direct effects on experience of competence and interest

\begin{tabular}{l|l|l|l|l|l|l}
\hline \multirow{2}{*}{ Variable } & \multicolumn{5}{l|}{ Experience of competence } & \multicolumn{4}{l}{ Interest at post-test } \\
\cline { 2 - 8 } & $95 \%$ CI & \multicolumn{2}{l}{$95 \%$ CI } & \\
\cline { 2 - 8 } & $\beta$ & $L L$ & $U L$ & $\beta$ & $L L$ & $U L$ \\
\hline Predictor & & & & & & \\
\hline Prior interest & $0.21^{*}$ & 0.07 & 0.35 & $0.64^{*}$ & 0.53 & 0.74 \\
\hline Treatment condition & $0.14^{*}$ & 0.04 & 0.25 & 0.05 & -0.04 & 0.14 \\
\hline Intervening variable & & & & & & \\
\hline Experience of competence & & & & -0.04 & -0.16 & 0.07 \\
\hline
\end{tabular}

Note CI Confidence interval; $L L$ Lower limit; UL Upper limit

*Significant regression coefficient (zero not included in the $95 \% \mathrm{CI}$ ) 


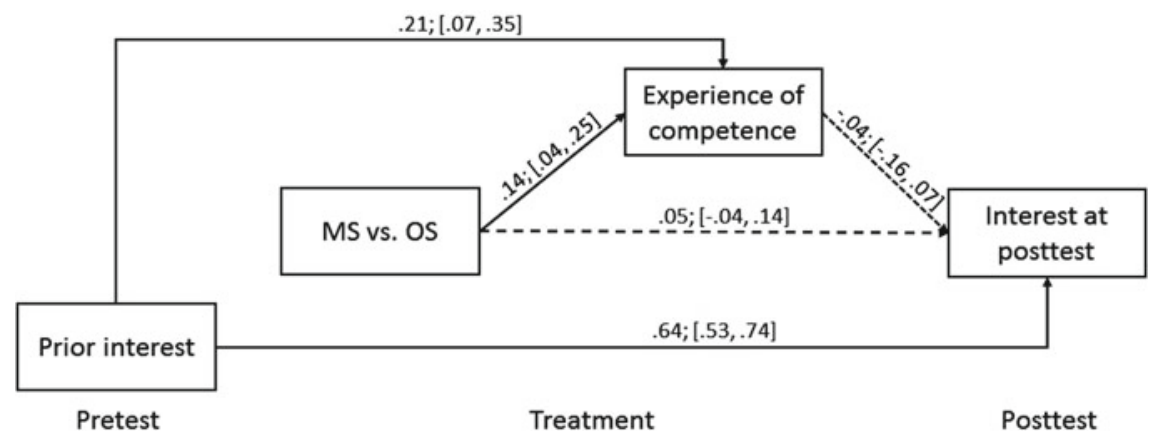

Fig. 3.6 Graphical illustration of direct effects in the path model. Note Significant paths are illustrated with solid lines, and nonsignificant paths are illustrated with a broken line

$=-0.01 ; 95 \% \mathrm{CI}[-0.04,0.02])$. Yet, there is still a total effect of prior interest on interest at post-test $(\beta=0.63 ; 95 \% \mathrm{CI}[0.53,0.73])$.

\subsection{Discussion}

The effects of constructing multiple solutions for real-world problems on students' interest and experience of competence address an important issue in mathematics education. Even though there are theoretical models about the development of interest and empirical results about the connection between students' basic needs and interestrelated measures, there has not been a brought range of information about how these needs influence students' interest. In this study, we analysed the influence of students' interest on their experience of competence and vice versa. Moreover, we investigated the effects of constructing multiple solutions, which only a few randomized experimental studies have investigated so far, on students' interest and experience of competence. In addition and to the best of our knowledge, there is only one study that analysed these effects on the basis of real-world problems, although these problems should be used in the classroom because of their importance for students' current and future lives. In our current study, we used the topic of linear functions to assess our research questions and used path analysis to determine the impact of constructing multiple solutions on students' interest.

On the basis of theoretical considerations and empirical results we predicted that constructing multiple solutions by applying different mathematical procedures would directly affect students' interest. However, the results of our study did not confirm this prediction. Students in the multiple solution condition and one solution condition reported on a similar level of interest at post-test after the four-lesson teaching unit. This result is in contrast to previous findings (Schukajlow \& Krug, 2014) that did identify effects of constructing multiple solutions by making different assumptions for vague conditions on students' interest. One possible explanation for this finding is 
that the approaches differed between this study and the previous one. In the current study, students in the MS condition had to use specific mathematical procedures, which were presented at the beginning of the teaching unit, and were not given the opportunity to choose their own individual routes to the solution during the teaching units as they had in the previous study (Schukajlow \& Krug, 2014).

As expected, we found a significant difference in the experience of competence between the MS condition and the OS condition. Thus, constructing multiple solutions can foster not only performance, conceptual knowledge, and cognitive flexibility (Levav-Waynberg \& Leikin, 2012; Rittle-Johnson et al., 2009; Star \& RittleJohnson, 2008) but also a basic need. This result is in line with the study by Schukajlow and Krug (2014) in which they revealed the importance of prompting students to construct multiple solutions for real-world problems with vague conditions for students' experience of competence. Therefore, we were able to extend the research on basic needs (e.g., Krapp, 2005; Renninger \& Hidi, 2002) by finding that students' experience of competence tended to be higher in the multiple solutions treatment conditions of the current and previous study. Furthermore, the findings confirm the view that instructional conditions can have an effect on students' individual interest (Hidi \& Renninger, 2006). Because students in both conditions all worked in groups on the same type of tasks and experienced the roughly the same methodological order, we argue that this is due to the prompts to use, to contrast and to compare two mathematical procedures in the MS-condition.

In order to explore how constructing multiple solutions by applying different mathematical procedures and students' prior interest would influence students' interest at post-test, we examined our hypothesised path model. As expected, the path model provided a good fit to the data according a combination of cutoff values ( $\mathrm{Hu} \&$ Bentler, 1999).

No indirect effects of constructing multiple solutions on students' interest at post-test were found. This result is in contrast to previous findings (Schukajlow \& Krug, 2014) and we argue that the lack of opportunity to choose their own solution routes might have negatively affected students' experience of autonomy and thus also impeded students' interest (Deci \& Ryan, 2000; Krapp, 2005). Another explanation for why our expectation for the positive influence of multiple solutions on interest was not confirmed emerges from the similarity of the tasks that were presented in the classroom in the present study. The real-world problems that were presented in the MS or OS condition were based on the same context, included the same numbers, and differed only in whether students were supposed to apply one or two mathematical procedures. It seems that this prompt positively influences students' perceived competence, but have not increased their interest. Trying to actively match the contexts to students' personal backgrounds and preferences in order to trigger their interest $(\mathrm{Ku}$ \& Sullivan, 2002; López \& Sullivan, 1992) or giving them the opportunity to choose their preferred contexts during the teaching unit are important aspects that can have a positive influence on interest. The roles of these aspects for interest-related measures needs to be investigated in future studies. Further, students report on a significant higher experience of competence in the presents study compared to previous study (Schukajlow \& Krug, 2014), the mean values for experience of competence in the 
present study were nearby the theoretical maximum of 5 and the standard deviation of experience of competence was lower than in the previous study. As interest in mathematical problems was found to be positively connected to task difficulty (Rellensmann \& Schukajlow, 2017), offering students more difficult problems during the teaching unit might increase the variance in students' experiences of competence and affect students' interest positively. Lastly, students' individual interest is a stable construct of a predisposition (Schukajlow et al., 2017) and an intervention of $180 \mathrm{~min}$ might just not be enough to have an impact.

The relevance of students' prior interest to their experiences of competence as well as their interest at post-test was another point we investigated. Previous studies have shown the relationship of competence-related measures and interest (Zimmerman \& Kitsantas, 1997). However, the direction of this connection was not completely clear (Hidi, 2006). The results of our study show that students' prior interest positively influences their experiences of competence, while a higher experience of competence during the teaching unit did not lead to a higher interest at post-test. Conclusively, there are no indirect effects of prior interest on students' interest at post-test via their experience of competence. As there are still total effects (which are the sum of all direct and indirect effects) of students' prior knowledge on their interest at post-test, we conclude that the experience of competence is not a transmitting variable for the effects of prior interest and the treatment condition on the interest at post-test. However, concerning the influence of prior interest for interest at post-test, we could confirm that interest is a stable construct, as prior interest had a high positive influence on interest at post-test.

\subsection{Strengths and Limitations}

The effects of the treatment condition and prior interest on experience of competence and on interest at post-test was explored using inferential and path analyses. Because the teaching method was actively manipulated, causal interpretations of the effects of multiple solutions on the outcome variables are allowed. However, such causal interpretations of paths in the path model should be made with caution. The validity of the analysis of path models depends on the times at which the data were collected and on evidence from previous research. We collected data before (prior interest), during (experience of competence) and after the teaching unit (interest at post-test), so that the data would be ordered along a timeline. Thus, it was possible to determine the direction of the effects and to examine the path model.

The assumed path model was derived from theories about interest (Krapp, 2000; Hidi \& Renninger, 2006) and the self-determination theory of human motivation (Deci \& Ryan, 2000). The results of previous empirical studies have inspired the hypothesised path between the treatment condition, students' experience of competence and their interest. One limitation derives from a possible incompleteness of the path model, as other intervening variables might need to be included. Interest, for example, has in contrast to other cognitively driven motivational variables both 
an affective and a cognitive component (Hidi, 2006). Experiencing interest involves affect from the outset of experience and can be assumed to be combined or integrated with cognition as it develops (Hidi \& Renninger, 2006; Krapp, 2000). Thus, positive and negative affect during the teaching unit as well as other cognitive variables could be important variables, which need to be considered in further analyses. One starting point is, that the experience of competence has been shown to be connected to students' autonomy, social relatedness, and intrinsic motivation. Thus, the other two basics needs should be included in future studies, in order to validate our findings. Positive effects of constructing multiple solutions for real-world problems by applying multiple mathematical procedures on these variables can be expected and transmitted on students' interest at post-test. This hypothesis should be tested in future studies using a corresponding mediation model that takes into account affective (e.g. enjoyment and boredom) and cognitive (e.g. experience of competence, experience of autonomy and experienced meaningfulness of the learning content) variables could be useful for further decomposing the effects on students' interest and should be applied in future studies.

\subsection{Conclusion}

Constructing multiple solutions is an important theme that has been investigated in research frameworks about the impact of comparison (Rittle-Johnson \& Star, 2007, 2009; Rittle-Johnson, Star, \& Durkin, 2009; Star \& Rittle-Johnson, 2008, 2009) and in experimental studies (Schukajlow \& Krug, 2014; Schukajlow et al., 2015). Our current is an extension to the previous experimental studies on constructing multiple solutions for real-world problems by making different assumptions about vague conditions. The aim of the study was to explore the effects of constructing a different kind of multiple solutions (using different mathematical procedures) on students' experience of competence and their interest. The inferential and path analyses, which were based on theories about interest and the self-determination theory, showed a positive influence of constructing multiple solutions on experience of competence but not on individual interest. However, the effects might be different for other affective variables. For example, we found positive indirect effects of constructing multiple solutions on self-efficacy via experience of competence for students' with low prior self-efficacy (Schukajlow, Achmetli, \& Rakoczy, in press).

\section{References}

Achmetli, K., Schukajlow, S., \& Krug, A. (2014). Effects of prompting students to use multiple solution methods while solving real-world problems on students' self-regulation. In C. Nicol, S. Oesterle, P. Liljedahl, D. Allan (Eds.), Proceedings of the Joint Meeting of PME 38 and PME-NA 36 (pp. 1-8). Vancouver, Canada: PME. 
Baron, R. M., \& Kenny, S. A. (1986). The moderator-mediator variable distinction in social psychological research: Conceptual, strategic, and statistical considerations. Journal of Personality and Social Psychology, 51(6), 1173-1182.

Bikner-Ahsbahs, A. (2004). Interest-dense situations and their mathematical valences. Contribution to the topic study group 24 on students' motivations and attitudes towards mathematics and its study. In 10th International Congress for Mathematics Education. Copenhagen, Denmark. Retrieved from http://www.math.uni-bremen.de/didaktik/ma/bikner/articles/article1.pdf.

Blum, W., Galbraith, P. L., Henn, H.-W., \& Niss, M. (2007). Modelling and applications in mathematics education. The 14th ICMI study. New York, NY: Springer.

Blum, W., \& Leiss, D. (2007). How do students and teachers deal with mathematical modelling problems? The example sugarloaf and the DISUM project. In C. Haines, P. L. Galbraith, W. Blum, \& S. Khan (Eds.), Mathematical modelling (ICTMA 12): Education, engineering and economics (pp. 222-231). Chichester, UK: Horwood.

Boekaerts, M., \& Corno, L. (2005). Self-regulation in the classroom: A perspective on assessment and intervention. Applied Psychology, 54(2), 199-231.

Carmichael, C. S., Callingham, R., Watson, J. M., \& Hay, I. (2009). Factors influencing the development of middle school students' interest in statistical literacy. Statistics Education Research Journal, 8(1), 62-81.

Deci, E. L. (1998). The relation of interest to motivation and human needs: The self-determination theory viewpoint. In L. Hoffmann, A. Krapp, K. A. Renninger, \& J. Baumert (Eds.), Interest and Learning. Proceedings of the Seeon-Conference on Interest and Gender (pp. 146-162). Kiel, Germany: IPN.

Deci, E. L., \& Ryan, A. M. (2000). The „What” and „Why” of goal pursuits: Human needs and the selfdetermination of behavior. Psychological Inquiry, 11(4), 227-268.

Deci, E. L., \& Ryan, R. M. (1991). A motivational approach to self: Integration in personality. In R. A. Dienstbier (Ed.), Perspectives on motivation (pp. 237-288). Lincoln, NE: University of Nebraska Press.

Deci, E. L., \& Ryan, R. M. (2008). Self-determination theory: A macrotheory of human motivation, development, and health. Canadian Psychology/Psychologie Canadienne, 49(3), 182-185.

Di Martino, P., Gómez-Chacón, I., Liljedahl, P., Morselli, F., Pantziara, M., \& Schukajlow, S. (2015). Introduction to the papers of TWG08: Affect and mathematical thinking. In Proceedings of the Ninths Congress of the European Society for Research in Mathematics Education. Prague: Czech Republic, Charles University of Prag.

Fisher, P. H., Dobbs-Oates, J., Doctoroff, G. L., \& Arnold, D. H. (2012). Early math interest and the development of math skills. Journal of Educational Psychology, 104(3), 673-681.

Frenzel, A. C., Pekrun, R., Dicke, A.-L., \& Goetz, T. (2012). Beyond quantitative decline: Conceptual shifts in adolescents' development of interest in mathematics. Developmental Psychology, 48(4), 1069-1082.

Galbraith, P. L., \& Stillman, G. (2006). A framework for identifying student blockages during transitions in the modelling process. ZDM Mathematics Education, 38(2), 143-162.

Große, C. S. (2014). Mathematics learning with multiple solution methods: effects of types of solutions and learners' activity. Instructional Science, 42(5), 715-745.

Große, C. S., \& Renkl, A. (2006). Effects of multiple solution methods mathematics learning. Learning and Instruction, 16(2), 122-138.

Guay, F., Boggiano, A. K., \& Vallerand, R. J. (2001). Autonomy support, intrinsic motivation, and perceived competence. Conceptual and empirical linkages. Personality and Social Psychology Bulletin, 27(6), 643-650.

Hannula, M. S. (2006). Motivation in mathematics: Goals reflected in emotions. Educational Studies in Mathematics, 63, 165-178.

Hänze, M., \& Berger, R. (2007). Cooperative learning, motivational effects, and student characteristics: An experimental study comparing cooperative learning and direct instruction in 12th grade physics classes. Learning and Instruction, 17(1), 29-41. 
Harackiewicz, J. M., Durik, A. M., Barron, K. E., Linnenbrink-Garcia, L., \& Tauer, J. M. (2008). The role of achievement goals in the development of interest: Reciprocal relations between achievement goals, interest, and performance. Journal of Educational Psychology, 100(1), 105-122.

Harter, S., Whitesell, N. R., \& Kowalski, P. (1992). Individual differences in the effects of educational transitions on young adolescents' perceptions of competence and motivational orientation. American Educational Research Journal, 29(4), 777-808.

Heinze, A., Reiss, K., \& Rudolph, F. (2005). Mathematics achievement and interest in mathematics from a differential perspective. ZDM Mathematics Education, 37(3), 212-220.

Hidi, S. (2006). Interest: A unique motivational variable. Educational Research Review, 1(2), 69-82.

Hidi, S., \& Renninger, K. A. (2006). The four phase model of interest development. Educational Psychologist, 41(2), 111-127.

Hidi, S., Renninger, K. A., \& Krapp, A. (2004). Interest, a motivational variable that combines affective and cognitive functioning. In D. Y. Dai \& R. J. Sternberg (Eds.), Motivation, emotion, and cognition: Integrative perspectives on intellectual functioning and development (pp. 89-115). Mahwah, NJ: Lawrence Erlbaum Associates.

Hiebert, J., Gallimore, R., Garnier, H., Givvin, K. B., Hollingsworth, H., Jacobs, J., et al. (2003). Teaching mathematics in seven countries. Results from the TIMSS 1999 video study. Washington, DC: NCES.

Hu, L., \& Bentler, P. M. (1999). Cutoff criteria for fit indexes in covariance structure analysis: Conventional criteria versus new alternatives. Structural Equation Modeling, 6(1), 1-55.

Kline, R. B. (2005). Principles and practice of structural equation modeling. New York, NY: Guilford Press.

Köller, O., Baumert, J., \& Schnabel, K. (2000). Zum Zusammenspiel von schulischem Interesse und Lernen im Fach Mathematik: Längsschnittanalysen In den Sekundarstufen I und II. In U. Schiefele \& E. Wild. (Eds.), Interesse und Lernmotivation (pp. 163-181). Münster: Waxmann.

Köller, O., Baumert, J., \& Schnabel, K. (2001). Does interest matter? The relationship between academic interest and achievement in mathematics. Journal for Research in Mathematics Education, 32(5), 448-470.

Krapp, A. (1999). Interest, motivation and learning: An educational-psychological perspective. European Journal of Psychology of Education, 14(1), 23-40.

Krapp, A. (2000). Interest and human development during adolescence: An educationalpsychological approach. In J. Heckhausen (Ed.), Motivational psychology of human development (pp. 109-128). Amsterdam, The Netherlands: Elsevier.

Krapp, A. (2005). Basic needs and the development of interest and intrinsic motivational orientations. Learning and Instruction, 15, 381-395.

Krug, A., \& Schukajlow, S. (2013). Problems with and without connection to reality and students' task-specific interest. In A. M. Lindmeier \& A. Heinze (Eds.), Proceedings of the 37th Conference of the International Group for the Psychology of Mathematics Education (pp. 209-216). Kiel, Germany: PME.

Ku, H.-Y., \& Sullivan, H. J. (2002). Student performance and attitudes using personalized mathematics instruction. Educational Technology Research and Development, 50(1), 21-34.

Kunter, M. (2005). Multiple Ziele im Mathematikunterricht [Multiple goals in mathematics lessons]. Münster, Germany: Waxmann.

Leikin, R., \& Lev, M. (2007). Multiple solution tasks as a magnifying glass for observation of mathematical creativity. In J.-H. Woo, H.-C. Lew, K.-S. P. Park, \& D.-Y. Seo (Eds.), Proceedings of the 31st International Conference for the Psychology of Mathematics Education (pp. 161-168). Seoul, Korea: PME.

Lerkkanen, M.-K., Kiuru, N., Pakarinen, E., Viljaranta, J., Poikkeus, A.-M., Rasku-Puttonen, H., et al. (2012). The role of teaching practices in the development of children's interest in reading and mathematics in kindergarten. Contemporary Educational Psychology, 37(4), 266-279.

Levav-Waynberg, A., \& Leikin, R. (2012). The role of multiple solution tasks in developing knowledge and creativity in geometry. Journal of Mathematical Behavior, 31, 73-90. 
López, C. L., \& Sullivan, H. J. (1992). Effect of personalization of instructional context on the achievement and attitudes of Hispanic students. Educational Technology Research and Development, 40(4), 5-14.

Maaß, K. (2010). Classification scheme for modelling tasks. Journal für Mathematikdidaktik, 31(2), 285-311.

MacKinnon, D. P. (2008). Introduction to statistical mediation analysis. Routledge, UK: Taylor \& Francis.

MacKinnon, D. P., Lockwood, C. M., Hoffman, J. M., West, S. G., \& Sheets, V. (2002). A comparison of methods to test mediation and other intervening variable effects. Psychological Methods, 7(1), 83.

MacKinnon, D. P., Lockwood, C. M., \& Williams, J. (2004). Confidence limits for the indirect effect: Distribution of the product and resampling methods. Multivariate Behavioral Research, 39(1), 99-128.

Marcou, A., \& Lerman, S. (2007). Changes in students' motivational beliefs and performance in a self-regulated mathematical problem-solving environment. In D. Pitta-Pantazi \& G. Philippou (Eds.), European Research in Mathematics Education V. Proceedings of the Fifth Congress of the European Society for Research in Mathematics Education. Larnaca, Cyprus 22-26 February 2007 (pp. 288-297). Larnaca, Cyprus: ERME. Retrieved from http://www.mathematik.uni-dortmund. de/ erme/CERME5b/WG2.pdf.

Marsh, H. W., Trautwein, U., Lüdtke, O., Köller, O., \& Baumert, J. (2005). Academic self-concept, interest, grades, and standardized test scores: Reciprocal effects models of causal ordering. Child Development, 76(2), 397-416.

Minnaert, A., Boekaerts, M., \& Opdenakker, M.-C. (2008). The relationship between students' interest development and their conceptions and perceptions of group work. Unterrichtswissenschaft, 36(3), 216-236.

Mitchell, M. (1993). Situational interest: Its multifaceted structure in the secondary school mathematics classroom. Journal of Educational Psychology, 85(3), 424-436.

Muthén, B. O., Muthén, L. K., \& Asparouhov, T. (2016). Regression and mediation analysis using Mplus. Los Angeles, CA: Muthén \& Muthén.

Muthén, B. O., \& Satorra, A. (1995). Complex sample data in structural equation modeling. Sociological Methodology, 25, 267-316.

Muthén, L. K., \& Muthén, B. O. (1998-2012). Mplus user's guide. Los Angeles, CA: Muthén \& Muthén.

National Council of Teachers of Mathematics. (2000). Principles and standards for school mathematics. Reston, VA: NCTM.

Neubrand, M. (2006). Multiple Lösungswege für Aufgaben: Bedeutung für Fach, Lernen, Unterricht und Leistungserfassung [Multiple procedures for problems: importance for content, learning, teaching and measurement of performance]. In W. Blum, C. Drüke-Noe, R. Hartung \& O. Köller. Bildungsstandards Mathematik: Konkret. Sekundarstufe I: Aufgabenbeispiele, Unterrichtsanregungen, Fortbildungsideen [Standards for school mathematics on the low-secondary level: tasks, ideas for teaching and teacher training] (pp. 162-177). Berlin, Germany: Cornelsen.

Niss, M., Blum, W., \& Galbraith, P. L. (2007). Introduction. In W. Blum, P. L. Galbraith, H.-W. Henn, \& M. Niss (Eds.), Modelling and applications in mathematics education: The 14th ICMI study (pp. 1-32). New York, NY: Springer.

Panaoura, A., Gagatsis, A., \& Demetriou, A. (2009). An intervention to the metacognitive performance: Self-regulation in mathematics and mathematical modeling. Acta Didactica Universitatis Comenianae Mathematics, 9, 63-79.

Pekrun, R., vom Hofe, R., Blum, W., Frenzel, A. C., Goetz, T., \& Wartha, S. (2007). Development of mathematical competencies in adolescence: The PALMA longitudinal study. In M. Prenzel. Studies on the educational quality of schools. The final report on the DFG priority programme (pp. 17-37). Münster, Germany: Waxmann.

Peugh, J. L., \& Enders, C. K. (2004). Missing data in educational research: A review of reporting practices and suggestions for improvement. Review of Educational Research, 74(4), 525-556. 
Pintrich, P. R. (1999). The role of motivation in promoting and sustaining self-regulated learning. International Journal of Educational Research, 31, 459-470.

Pollak, H. (1979). The interaction between mathematics and other school subjects. In UNESCO (Ed.), New trends in mathematics teaching IV (pp. 232-248). Paris, France: UNESCO.

Rellensmann, J., \& Schukajlow, S. (2017). Does students' interest in a mathematical problem depend on the problem's connection to reality? An analysis of students interest and pre-service teachers judgments of students' interest in problems with and without a connection to reality. ZDM Mathematics Education, 49(3), 367-378.

Renninger, K. A., \& Hidi, S. (2002). Student interest and achievement: Developmental issues raised by a case study. In A. Wigfield \& J. S. Eccles (Eds.), Development of achievement motivation (pp. 173-195). San Diego, CA: Academic Press.

Rittle-Johnson, B., \& Star, J. R. (2007). Does comparing solution methods facilitate conceptual and procedural knowledge? An experimental study on learning to solve equations. Journal of Educational Psychology, 99(3), 561-574.

Rittle-Johnson, B., \& Star, J. R. (2009). Compared with what? The effects of different comparisons on conceptual knowledge and procedural flexibility for equation solving. Journal of Educational Psychology, 101(3), 529-544.

Rittle-Johnson, B., Star, J. R., \& Durkin, K. (2009). The importance of prior knowledge when comparing examples: Influences on conceptual and procedural knowledge of equation solving. Journal of Educational Psychology, 101(4), 836-852.

Ryan, R. M., \& Deci, E. L. (2000). Self-determination theory and the facilitation of intrinsic motivation, social development, and well-being. American Psychologist, 55, 68-78.

Schafer, J. L., \& Graham, J. W. (2002). Missing data: Our view of the state of the art. Psychological Methods, 7(2), 147-177.

Schiefele, U., Krapp, A., \& Schreyer, I. (1993). Metaanalyse des Zusammenahngs von Interesse und schulischer Leistung. Zeitschrift für Entwicklungspsychologie und Pädagogische Psychologie, 25, $120-148$.

Schiefele, U., \& Schreyer, I. (1994). Intrinsische Lernmotivation und Lernen. Ein Überblick zu Ergebnissen der Forschung. Zeitschrift für Pädagogische Psycholgie, 8, 1-13.

Schukajlow, S., Achmetli, K., \& Rakoczy, K. (2019). Does constructing multiple solutions for real-world problems affect self-efficacy. Educational Studies in Mathematics, 100, 43-60.

Schukajlow, S., Blum, W., Messner, R., Pekrun, R., Leiss, D., \& Müller, M. (2009). Unterrichtsformen, erlebte Selbständigkeit, Emotionen und Anstrengung als Prädiktoren von SchülerLeistungen bei anspruchsvollen mathematischen Modellierungsaufgaben [Teaching methods, perceived self-regulation, emotions, and effort as predictors for students' performance while solving mathematical modelling tasks]. Unterrichtswissenschaft, 37(2), 164-186.

Schukajlow, S., \& Krug, A. (2012a). Effects of treating multiple solutions on students' selfregulation, self-efficacy and value. In T. Y. Tso (Ed.), Proceedings of the 36th Conference of the International Group for the Psychology of Mathematics Education (pp. 59-66). Taipei, Taiwan: PME.

Schukajlow, S. \& Krug, A. (2012b). Treating multiple solutions in the classroom and their influence on students' achievements and the affect-Theoretical background and design of the quasiempirical study. In ICME 12 Conference (pp. 3414-3422). Seoul, Korea: ICME.

Schukajlow, S., \& Krug, A. (2014). Do multiple solutions matter? Prompting multiple solutions, interest, competence, and autonomy. Journal for Research in Mathematics Education, 45(4), 497-533.

Schukajlow, S., Krug, A., \& Rakoczy, K. (2015). Effects of prompting multiple solutions for modelling problems on students' performance. Educational Studies in Mathematics, 89(3), 1-25.

Schukajlow, S., Leiss, D., Pekrun, R., Blum, W., Müller, M., \& Messner, R. (2012). Teaching methods for modelling problems and students' task-specific enjoyment, value, interest and selfefficacy expectations. Educational Studies in Mathematics, 79(2), 215-237. 
Schukajlow, S., Rakoczy, K., \& Pekrun, R. (2017). Emotions and motivation in mathematics education: Theoretical considerations and empirical contributions. ZDM Mathematics Education, 49(3), 307-322.

Silver, E. A., Ghousseini, H., Gosen, D., Charalambous, C. Y., \& Font Strawhun, B. T. (2005). Moving from rhetoric to praxis: Issues faced by teachers in having students consider multiple solutions for problems in the mathematics classroom. Mathematical Behavior, 24(3-4), 287-301.

Slavin, R. E., Hurley, E. A., \& Chamberlain, A. (2003). Cooperative learning and achievement: Theory and research. In W. M. Reynolds \& G. E. Miller (Eds.), Handbook of psychology: Educational psychology (pp. 177-198). New York, NY: Wiley.

Star, J. R., \& Rittle-Johnson, B. (2008). Flexibility in problem solving: The case of equation solving. Learning and Instruction, 18, 565-579.

Star, J. R., \& Rittle-Johnson, B. (2009). It pays to compare: An experimental study on computational estimation. Journal of Experimental Child Psychology, 102(4), 408-426.

Verschaffel, L., Greer, B., \& De Corte, E. (2000). Making sense of word problems. Lisse, The Netherlands: Swets and Zeitlinger.

Webb, N. M., \& Palincsar, A. S. (1996). Group processes in the classroom. In D. C. Berliner \& R. C. Calfee (Eds.), Handbook of educational psychology (pp. 841-873). New York, NY: Macmillan.

Wigfield, A., Battle, A., Keller, L. B., \& Eccles, J. S. (2002). Sex differences in motivation, selfconcept, career aspiration, and career choice: Implications for cognitive development. In R. De Lisi \& A. McGillicuddy-De Lisi (Eds.), The development of sex differences in cognition (pp. 93-124). Westport, CT: Ablex Publishing.

Wigfield, A., \& Cambria, J. (2010). Students' achievement values, goal orientations, and interest: Definitions, development, and relations to achievement outcomes. Developmental Review, 30, $1-35$.

Wigfield, A., \& Eccles, J. S. (2000). Expectancy-value theory of achievement motivation. Contemporary Educational Psychology, 25, 68-81.

Zimmerman, B. J., \& Kitsantas, A. (1997). Developmental phases in self-regulation: Shifting from process goals to outcome goals. Journal of Educational Psychology, 89(1), 29-36.

Zimmerman, B. J., \& Schunk, D. H. (Eds.). (2001). Selfregulated learning and academic achievement: Theoretical perspectives. Mahwah, NJ: Erlbaum.

Open Access This chapter is licensed under the terms of the Creative Commons Attribution 4.0 International License (http://creativecommons.org/licenses/by/4.0/), which permits use, sharing, adaptation, distribution and reproduction in any medium or format, as long as you give appropriate credit to the original author(s) and the source, provide a link to the Creative Commons license and indicate if changes were made.

The images or other third party material in this chapter are included in the chapter's Creative Commons license, unless indicated otherwise in a credit line to the material. If material is not included in the chapter's Creative Commons license and your intended use is not permitted by statutory regulation or exceeds the permitted use, you will need to obtain permission directly from the copyright holder.

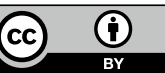

